\title{
New goals and new models of College English Teaching Maohua SUN
}

\author{
Foreign Language Department, Dalian Jiao Tong University, Liaoning Province, China \\ summer_817@163.com
}

Keywords: College English teaching, information technology, new mode

\begin{abstract}
The development of information technology is changing with each passing day, the demand of national strategy is constantly updated, the guide of College English teaching guides the direction, and the national evaluation system is gradually reformed. Against this background, different colleges and universities are constantly exploring new teaching objectives and developing new teaching models based on the needs of national development and the characteristics of our schools. This article focuses on the theme of "new goals and new models of College English Teaching". It shows the frontier development and innovation achievements of College English teaching reform.
\end{abstract}

\section{大学英语教学的新目标与新模式}

\author{
孙茂华 \\ 大连交通大学, 大连, 辽宁省, 中国 \\ summer_817@163.com
}

关键词:大学英语教学, 信息技术, 新模式

中文摘要.信息技术发展日新月异, 国家战略需求不断更新, 《大学英语教学指南》引领方向, 国家测评体系逐步改革。在这样的背景下, 不同的院校基于国家发展需求与本校特色, 不断探索 新的教学目标, 开发新的教学模式。本文围绕“大学英语教学的新目标与新模式”这一主题展开论 述。展示了大学英语教学改革的前沿发展与创新成果。

\section{1. 信息技术对大学英语教学产生的系统性影响}

信息技术不仅提供了新的资源、工具与方法, 也改变了高等教育, 包括大学英语的教学 目标、教学内容和教学模式。信息技术发展的背景下, 语言能力、教学材料、课程设置、教 学方法的不断发展变化。在语言能力方面, 外语教学逐步重视语言使用与生活结合, 以培养 21 世纪能力和交际能力 2.0 为目标, 并注重其人文教育的性质。这既体现了 《大学英语教学指 南》精神, 也与英语能力等级量表呼应。在教学材料方面, 信息化时代的教学材料以内容、 任务、项目或学科专业知识为体系, 体现个性化的特点。在课程设置方面, 具有中国特色的 新型“在线开放课程”。它应以学校为基础, 扩展至社会; 注重课程群建设; 寻求校际合作、 校企合作; 实现线上线下结合、免费与付费结合。在教学方法方面, 教师应积极实践任务式、 合作式、项目式、探究式等教学方法, 并探索混合式教学和合作学习等体现数字化发展趋势 的教学模式。 


\section{2. 大学英语教学需要充分考虑教学的有效性}

教学的有效性体现在能够达成教学目标、教学资源消耗低、学习能力提升快三个方面。 要实现有效教学, 大学英语教学应该实现四个目标转向, 即现代教育观到后现代教育观的转 向、现代知识观到后现代知识观的转向、基础范式到内容范式教学观的转向、英语综合技能 到核心学习能力培养目标的转向。现代教育观到后现代教育观的转向主要体现在知识权威性 在弱化, 经验间接性在强化, 学习自主性在提升, 学习生态圈在重构; 现代知识观到后现代 知识观的转向主要体现在知识的文化性和境域性; 基础范式到内容范式教学观的转向主要体 现在通用英语、专门用途英语、双语教学课程体系的构建; 英语综合技能到核心学习能力培 养目标的转向主要体现在英语阅读力、思考力、表达力的培养。

\section{3. 大学英语的教学改革与实践}

大学英语课程主体框架包括大学英语通识必修课和大学英语通识选修课。其中, 大学英 语通识必修课为不同需求与特点的学生设定了“基础”、“提高”、“发展”三个不同层次的目标, 并针对不同目标开设不同课程。特色类大学英语课程采用准专业化的培养模式, 实行小班授 课, 实施导师制, 培养语言应用能力、思辨能力和创新能力。艺体类大学英语课程则基于“互 联网+”的教育理念, 采用网络平台与课堂教学相结合的教学模式、形成性评价与期末口语考 试相结合的评价方式, 有效激发艺体类学生的学习积极性与学习潜能。为学生出国留学、考 研带来了很大帮助, 同时有效促进学生语言能力发展, 同时, 教学改革的过程也是教师发展 的过程。改革促使教

\section{4. 新时代大学英语学术素养导向教学实践}

大学英语学术素养指大学生英语学习过程中所应具备的学术能力及情感特质两个维度, 而以学术素养培养为导向的“教“与”学“是为践行高等教育要求而展开的素质养成行为及其动 态过程。大学英语学术素养导向理论体系包括理论基础 (学习中心说、产出导向法及学习共 同体等) 、教学假设 (学术素养后天培养、学术产出驱动、学术输入促成) 及实践流程 (探 索、内化与评估) 。理论基础是后两者的理论支撑, 教学假设是实践流程的指导思想, 实践 流程是前两者的落实路径。此体系旨在明确学术素养培养与大学英语课程之间的关系: 学术 素养培养是大学英语教育教学的逻辑起点, 充分体现课程的高等教育属性; 厘清大学英语课 程培养目标和课程类型之间的关系：通用英语与专用英语均为学术素养培养的有效路径。

\section{5. “慕课+翻转课堂”教学新模式}

大学英语拓展课程的目的是提高学生英语应用能力和英语素质; 类别分为语言技能提高 类、跨文化交际类和专门用途类。课程建设应坚持多元化、个性化和本土化的原则。教师应 先了解学生学习兴趣、明确国家发展所需、进行自我分析, 进而基于这三者的调研分析结果 进行拓展课程设置。慕课是大学英语拓展课程最好的借力手段。这一模式基于教材研发成果, 并在不同课程中应用, 其严密的实践流程为学生提供了有机结合的线上、线下任务, 并明确 了教师的重要角色。

\section{6. 新时代大学英语“线上线下”混合式教学模式的设计与实践}

“线上线下”总体框架由四个部分组成，包括“有效输入”、“人机交互”、“翻转课堂”和“过程 考核”四个环节。有效的语言输入必须建立在真实的语言信息、语言环境和语言交流基础上, 围绕课程教学大纲展开, 具有开放性与多样性。同时, 慕课在人机交互方面应体现精心的设 计与布局。翻转课堂的应用在混合式教学模式中具有重要作用, 应该与课程建设有机结合。 
万物生长, 生机盎然, “大学英语教学的新目标与新模式”亦是勃勃生机。形成百花齐放、 多元探索的大学英语教学新局面。

\section{References}

[1] Chen Jian Lin. The organic integration of computer network and foreign language curriculum under the new mode of College English teaching. foreign language audio-visual instruction, 2006 (12): 3-10.

[2] "Chen Qingsong and $\mathrm{Xu}$ Luo." web-based foreign language learning in College English Teaching "J\}. foreign language community, 2006 (6): 16-23.

[3] Ma Rui. On the influence of humanistic learning theory on modern teaching technology $\{J\}$. Chinese audio-visual education, 1996 (10).

[4] Ma Xiu Qi and Diao Xiuli. The value and application of modern humanistic education theory, $\{J\}$. audio-visual education research, $2002(9>)$.

[5] Gao Geely. An overview of foreign language learning in China. $\{\mathrm{J}\}$. foreign language teaching, 2005 (1): 60-63.

[6] Gao Peng and Zhang Xuezhong. The cultivation of learner autonomy in College English classroom $\{\mathrm{J}\}$. foreign language community, 2005 (1): 39-45.

[7] Fan Ye. On "learner training" in College English teaching $\{\mathrm{J}\}$. foreign language field, 1999 (3): 32-37. 